\title{
ISSUES IN PROBABILISTIC SEISMIC HAZARD ANALYSIS FOR NUCLEAR FACILITIES IN THE US
}

\author{
ROBIN K. MCGUIRE \\ Fugro William Lettis \& Assoc., 4155 Darley Avenue, Suite A, Boulder, CO 80305, USA \\ E-mail : mcguire@riskeng.com
}

Received October 31,2009

Probabilistic seismic hazard analysis (PSHA) is routinely conducted in the US for nuclear plants, for the determination of appropriate seismic design levels. These analyses incorporate uncertainties in earthquake characteristics in stable continental regions (where direct observations of large earthquakes are rare), in estimates of rock motions, in site effects on strong shaking, and in the damage potential of seismic shaking for engineered facilities. Performance goals related to the inelastic deformation of individual components, and related to overall seismic core damage frequency, are used to determine design levels. PSHA has the ability to quantify and document the important uncertainties that affect seismic design levels, and future work can be guided toward reducing those uncertainties.

KEYWORDS : Probabilistic Seismic Hazard Analysis, Performance-based Design

\section{INTRODUCTION}

Probabilistic seismic hazard analysis (PSHA) is routinely used to determine appropriate earthquake design loads for structures in the US, including for nuclear power plants. The field of PSHA has evolved significantly over the past 40 years, since the early work in this area by Cornell and Esteva (see Ref. 1). In spite of this evolution, several issues in the application of PSHA are being addressed in the current generation of PSHA studies in the US. This paper summarizes some of these issues, the reasons for them, and possible resolutions in the future. The emphasis here is on PSHA applications for nuclear power plant design that have occurred over the past 6 years in the eastern US.

\section{CHARACTERISTICS OF LARGE MAGNITUDE EARTHQUAKES IN STABLE CONTINENTAL REGIONS}

Estimating the characteristics of future, large magnitude earthquakes is always a challenge, and is especially difficult in stable continental regions (SCRs). In these regions the causative faults are often buried, so slip rates cannot be directly estimated from geologic evidence. The magnitudes of historic, pre-instrumental earthquakes must be inferred from qualitative observations, often with meager data, and inferences must be drawn from the area of felt shaking or the area of reported damage to structures.

Regarding the frequency of occurrence of large earthquakes, current work in the US on the 1811-1812 New Madrid, Missouri earthquakes (M 8.2) and the 1886 Charleston, South Carolina earthquake (M $\sim 7.2)$ concentrates on examining paleoliquefaction evidence. Indication of pre-historical earthquakes, and dating of deposits contained in paleoliquefaction geologic features, allow the number of large earthquakes that have occurred over a period of geologic time, and their spatial extent, to be estimated. These evaluations of the number of events, the time period, and the spatial extent have large uncertainties, leading to significant uncertainties in the mean recurrence interval. One complicating factor is the hypothesis that earthquakes occur in clusters, e.g. that 5 events may occur over a 2000-year period, with a mean recurrence interval of 500 years, followed by a quiescent period of 10,000 years. A simple argument supporting the cluster model is that without it, the number of earthquake occurrences in the Holocene, at the rates indicated by recent paleoliquefaction evidence, should have generated topographic features at the surface. Neither earthquake region listed above shows evidence of seismically induced topography.

An additional challenge in the US is the relatively short historical record. The earliest recorded earthquake in North America was in 1627 in the eastern part of the continent, but earthquakes were not routinely documented in other parts of the continent until the latter half of the $19^{\text {th }}$ century. While the New Madrid earthquakes, the Charleston earthquake, and the 1925 M 7 Charlevoix, Quebec earthquake occurred during historic times, it is likely that other seismic sources have caused $\mathbf{M} \geq 7$ 
earthquakes in eastern North America, and these other sources are difficult to identify and characterize.

\section{CHARACTERISTICS OF ROCK MOTION IN SCRS}

The fundamental property of SCRs is that they are tectonically stable and produce few earthquakes. As a result, earthquake ground motion estimates cannot be made empirically, because few instruments have recorded strong motions from these events. Methods that are used include theoretical methods (where ground motions are based on simple physical models of the source and of wave propagation through the earth), and semi-empirical methods (where empirical models from plate margin regions are modified to account for differences in the energy release at the source and in the attenuation of wave energy through the earth). The use of theoretical and semiempirical models leads to large uncertainties in the median ground motions for earthquakes in SCRs. This is illustrated

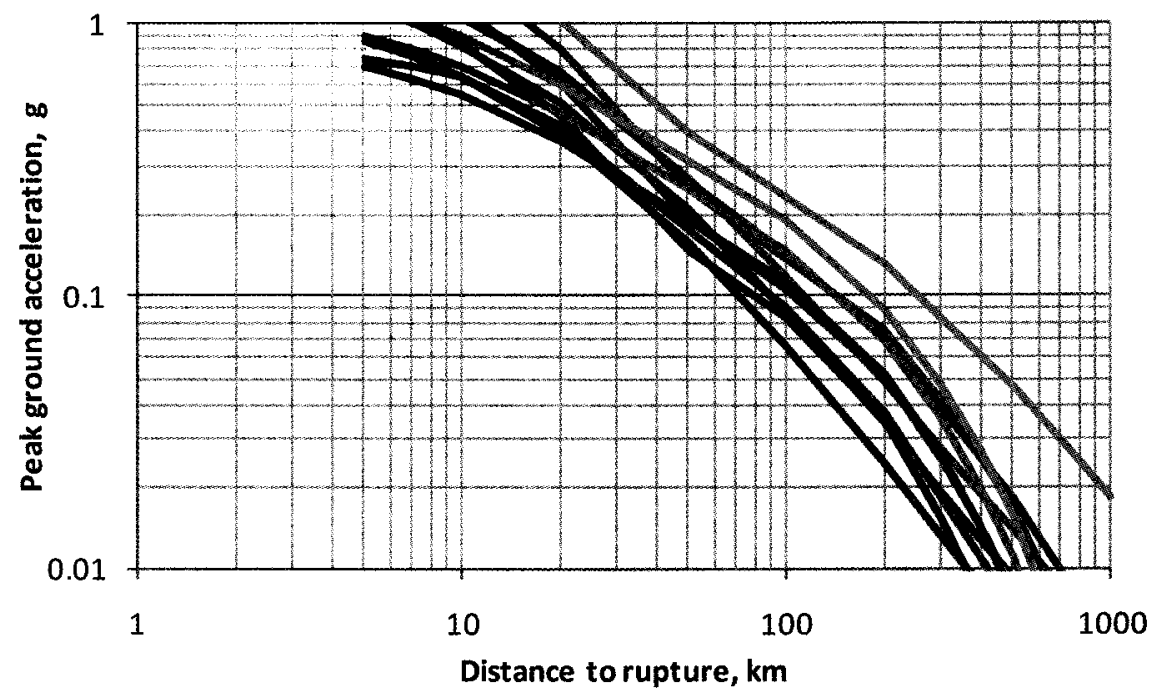

Fig. 1. Median Rock PGA for M 7.5 Earthquake vs. Distance for SCR Using 12 Models from Ref. 2

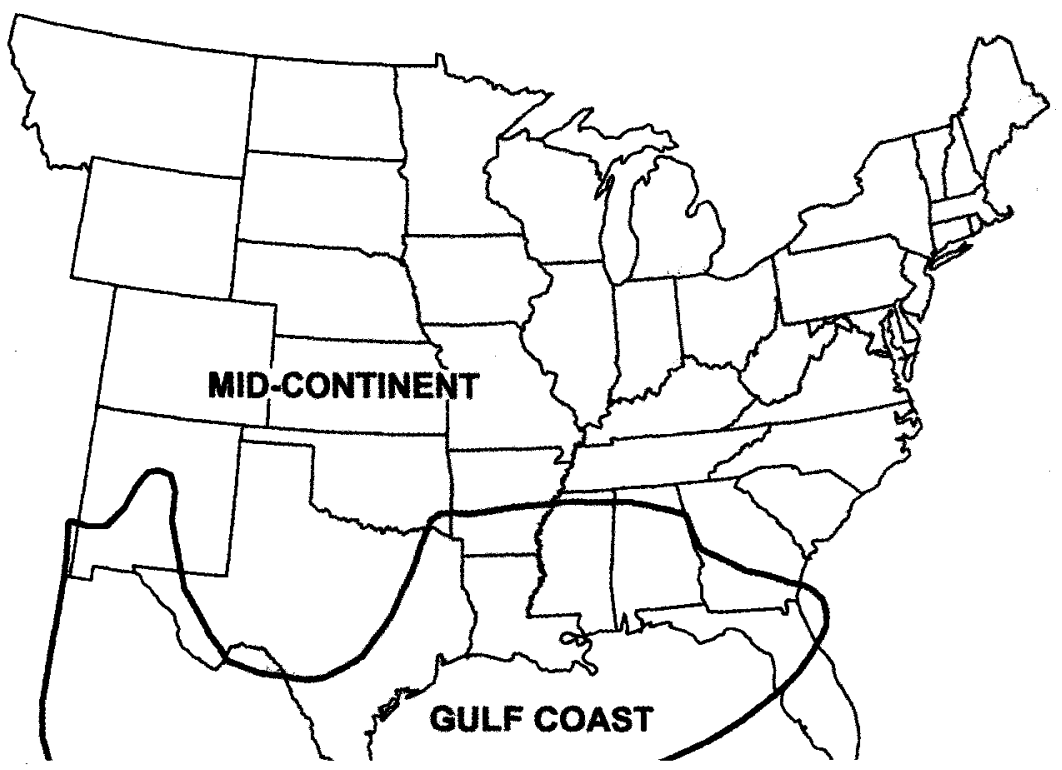

Fig. 2. Regions of Eastern US Attenuation: Mid-Continent and Gulf Coast. (Source: Ref. 2) 
in Figure 1, which compares median estimates of peak ground acceleration (PGA) for a $\mathbf{M} 7.5$ earthquake vs. distance, using 12 alternative models from Ref. 2 . Note that specific weights are assigned to each of the 12 models in Figure 1 (per Ref. 2), not equal weights. Note also that the models estimate PGA for hard-rock conditions $\left(V_{\mathrm{s} 30}\right.$ of $2800 \mathrm{~m} / \mathrm{s}$ ). The large uncertainty illustrated in Figure 1 is epistemic uncertainty, that is, it is a consequence of incomplete knowledge. This is separate from aleatory uncertainty, the randomness exhibited by recorded ground motion data, which is also an important parameter in PSHA.

The median PGA estimates illustrated in Figure 1 are for the Mid-Continent region of eastern North America, which includes the SCR. A different set of equations is recommended for the southern part of the US along the Gulf of Mexico coast (designated the Gulf Coast region). Figure 2 shows a map of the eastern US with the two regions identified. Both are within the intra-plate region of eastern North America. Figure 3 compares logarithmic mean PGA estimates for the two regions and illustrates the significant difference in attenuation between the two regions. This shows that, within intra-plate regions, more than one set of models may be necessary to estimate ground motion amplitudes.

The differences shown in Figure 3 emphasize that regional differences in ground motion attenuation are important. A research study funded by the US Nuclear Regulatory Commission, the US Dept. of Energy, and the Electric Power Research Institute is examining ground motion models that might be used to better characterize strong motions in this region, and results are expected in 2011. An additional issue that is not easily addressed generically is what set of models to use when parts of the source-to-site travel path lie in both regions.

\section{HOW TO INCORPORATE THE EFFECTS OF SITE CONDITIONS IN PSHA}

Most PSHA applications in the eastern US are not for hard rock, meaning that site conditions (soil or soft rock) must be taken into account. Incorporating site conditions into PSHA has received attention in recent years (Ref. 3, $4,5,6$ ). All of these references recognize the importance of incorporating uncertainties in site amplification into the PSHA in a consistent way. That is, one should not conduct a PSHA for rock conditions, and then convert uniform hazard response spectra (UHRS) by deterministic amplification factors for a site, to obtain the site-specific UHRS amplitudes.

For a site-specific PSHA at a proposed nuclear facility, details of the shear-wave velocity and degradation properties are usually available from geophysical measurements, and dynamic laboratory tests of subsurface layers are usually available, so that a site-specific calculation of site response can be made. Even with the site-specific detail, uncertainties in stiffness, damping, and shear-wave characteristics are inherent to the calculations. This is true for geologic units that have been sampled by drilling, and to a greater extent for geologic units below the deepest borehole at a site. These deep units must be characterized by extrapolation, analogy, and data (often containing only $\mathrm{p}$-wave measurements) from other boreholes in the vicinity.

Another source of uncertainty in site response is the incoming rock motion. The frequency content (amplitudes and spectral shape) of incoming seismic waves will affect the calculated site response. Even when the spectral shape and amplitude at a particular spectral frequency are fixed, different ground motions (with different wave phasings and durations) will cause different site response.

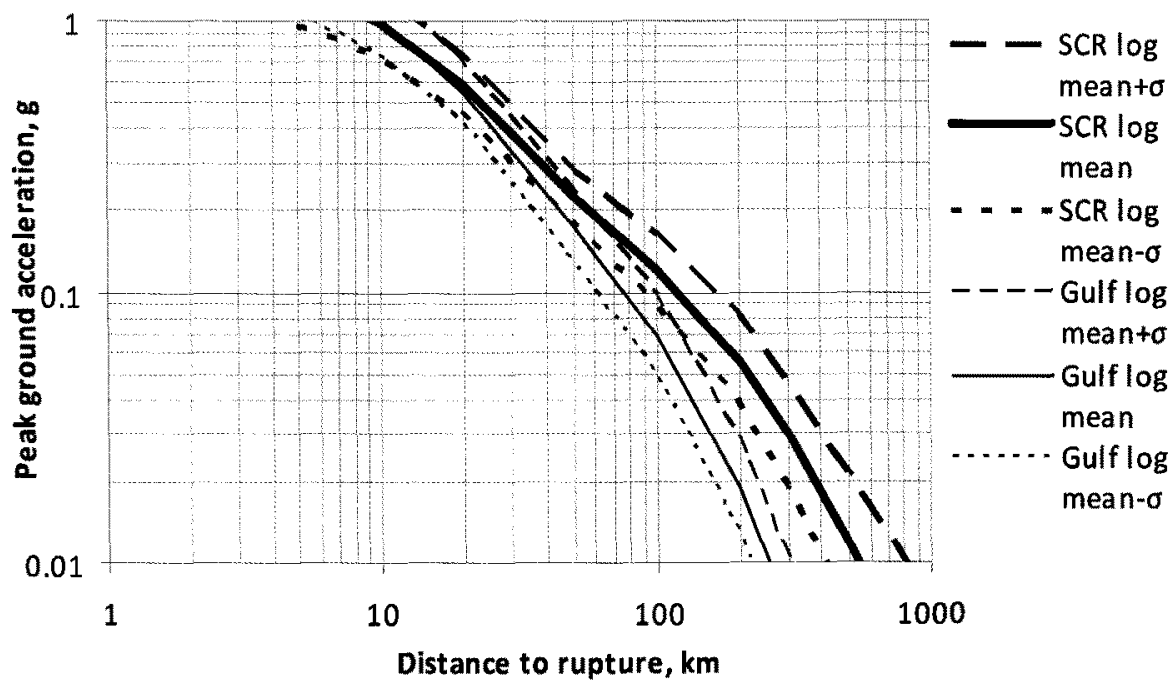

Fig. 3. Logarithmic Mean and Mean \pm o PGA Attenuation for M 7.5 for SCR and Gulf Coast Models 


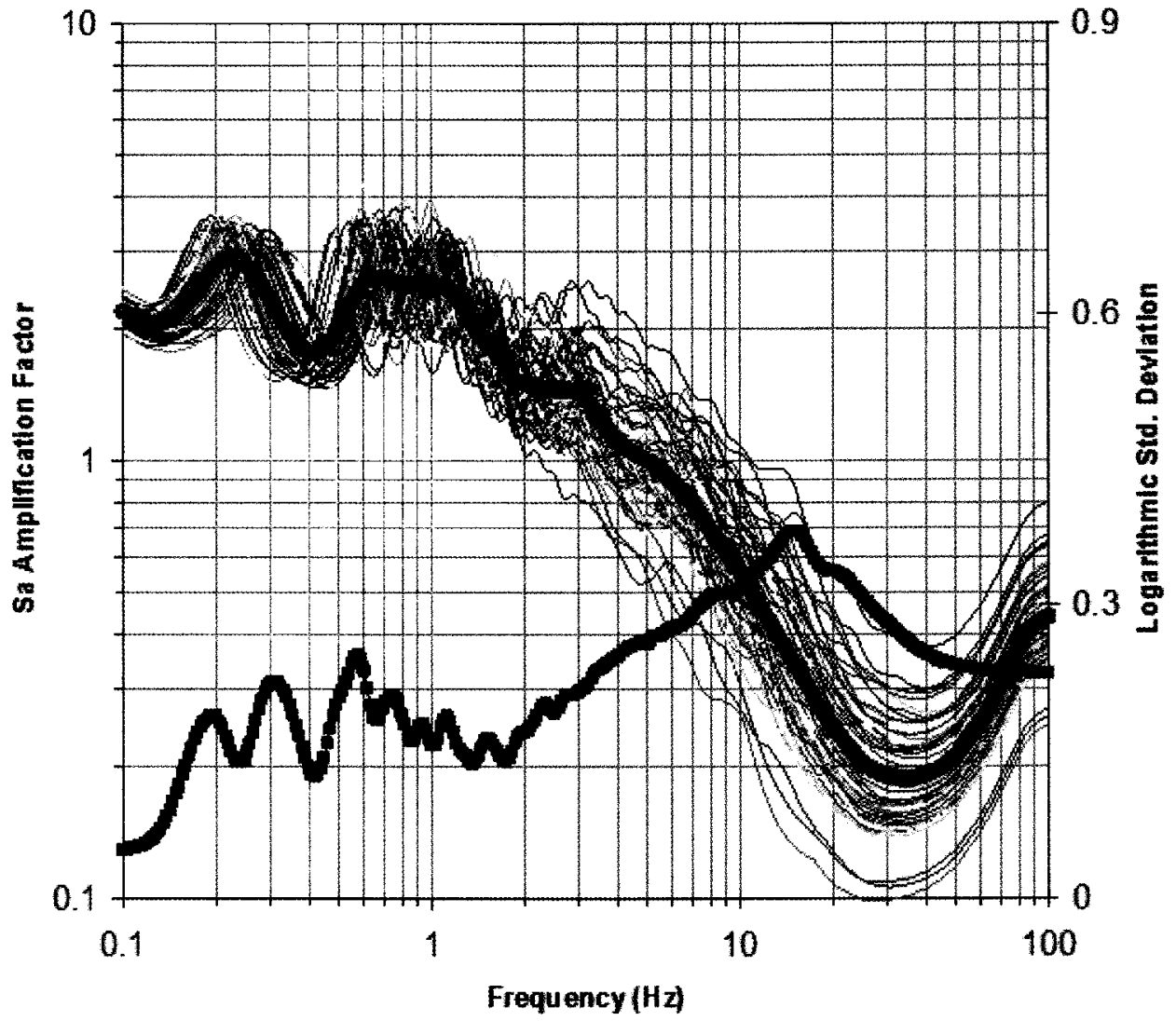

Fig. 4. Amplification Factors for a Deep Soil Site and for One Rock UHRS. The Thin Curves Indicate the Amplification Factors Calculated for 60 Synthetic Profiles that Represent Uncertainty in Site Characteristics; the Thick Grey Curve Indicates the Logarithmic Mean of the 60 Amplification Factors (Both Using the Left Scale). The Thick Black Line Indicates the Logarithmic Standard Deviation (Using the Right Scale) in Site Amplification (Source: Ref. 7)

Figure 4 (taken from Ref. 7) illustrates, for one rock UHRS, the mean and uncertainty in site amplification factor (spectral acceleration at the surface divided by spectral acceleration of rock input motion) for a deep soil site ( $800 \mathrm{~m}$ of soil above hard rock) located in the eastern US. This site had multiple borehole data to a depth of $120 \mathrm{~m}$, and estimates of soil properties below $120 \mathrm{~m}$ were made using other deeper borehole data in the vicinity. With these data, the uncertainty in site amplification factor is characterized by a logarithmic standard deviation of 0.2 to 0.3 . As an approximation, the effect of uncertainty in site response can be calculated for each spectral frequency $f$ as:

$$
a_{r p}^{s}(f)=a_{r p}(f) \overline{A F}_{r p} \exp \left[0.5 K_{H} \sigma_{\delta}^{2} /\left(1-K_{A F}\right)\right]
$$

where $a_{r p}^{s}(f)$ is spectral acceleration on soil at return period $r p$ and spectral frequency $f, a_{r p}(f)$ is spectral acceleration on rock at the same return period, $\overline{A F}_{r p}$ is the mean amplification factor (see Figure 4$), K_{H}$ is the (negative) log-log slope of the rock hazard curve, $\mathrm{K}_{\mathrm{AF}}$ is the (negative) $\log -\log$ slope of soil amplification vs. rock spectral acceleration, and $\sigma$ is the logarithmic standard deviation of soil amplification factor (see Fig. 4). Eqn. (1) is taken from eqn. (69) of Ref. 6 (with a correction). The exponential term in Eqn. (1) indicates the effect of uncertainty in site response on increasing the spectral acceleration on soil for a given return period motion. For typical uncertainties in site amplification the effect can increase soil ground motions by $20-30 \%$.

An issue related to site response is how to select earthquake motions to calculate site amplification factors. The site amplification factors illustrated in Figure 4 were calculated for one earthquake magnitude $\mathbf{M}$ and distance $\mathrm{R}$ that were chosen by deaggregation of the seismic hazard. The standard procedure in the US is to determine one $\mathbf{M}$ and $\mathrm{R}$ for the high frequency (e.g. $5-10 \mathrm{~Hz}$ ) part of the response spectrum, and a second $M$ and $R$ for the low frequency (e.g. 1-2.5 Hz) part of the response spectrum (Ref. 3,8 ). If there is a significant (i.e. $\geq 5 \%$ ) contribution to low frequency hazard from distances $>100 \mathrm{~km}$, the conditional $\mathbf{M}$ and $\mathrm{R}$ for those larger distances are used 
for the low frequency part of the spectrum. This works well in most applications, but when two sources of earthquakes have significant contributions to either the high- or low-frequency portion of the response spectrum, a single $\mathbf{M}$ and $\mathrm{R}$ may be a poor approximation that may result in an $\mathbf{M}$ and/or $\mathrm{R}$ that lies between the two sources. Thus the calculated $\mathbf{M}$ and $\mathrm{R}$ may represent an earthquake that does not affect the site. The most accurate procedure for future applications would be to calculate site response (including uncertainty) for every $\mathbf{M}$ and $\mathrm{R}$ included in the PSHA. This is defined as "Approach 4" in Ref. 9, and its main disadvantage is that it is very calculation-intensive.

\section{HOW TO ACCOUNT FOR NON-DAMAGING GROUND MOTIONS}

The nuclear power industry has long recognized that many short-duration, high-frequency ground motions are not damaging to engineered facilities, regardless of the spectral amplitudes of the motion (Ref. 10). The damageability of ground motions subsequently has been quantified by the Cumulative Absolute Velocity (CAV) (Ref. 11), which is a characteristic of recorded ground motions. It is calculated by summing absolute acceleration $\times$ incremental time steps, resulting on a quantity that has units of velocity, as follows:

$$
C A V=\sum_{i=1}^{N} H\left(p g a_{i}-0.025\right) \int_{t=t_{i}}^{t_{i+1}}|a(t)| d t
$$

where $\mathrm{H}$ is the Heaviside step function. Ref. 11 derives an equation for calculating the probability of ground motions exceeding a CAV value of $0.16 \mathrm{~g}$-sec, which is considered a conservative estimate of CAV for ground motions that will cause damage. The equation for $\mathrm{P}(\mathrm{CAV}>0.16 \mathrm{~g}-\mathrm{sec})$ depends on earthquake magnitude $\mathbf{M}$, PGA amplitude, site conditions (quantified by $\mathrm{V}_{\mathrm{S} 30}$ ), and duration of shaking (which can be estimated from $\mathbf{M}$ ). Figure 5, taken from Ref. 11, illustrates this equation for $V_{\mathrm{S} 30}=1000 \mathrm{~m} / \mathrm{s}$.

Use of the CAV equation is an improvement over the common practice of applying a lower-bound magnitude to the PSHA. In the eastern US, a lower bound bodywave magnitude of $\mathrm{m}_{\mathrm{bLg}}=5.0$ has typically been used, which corresponds to moment magnitude $\mathbf{M}=4.6$. When using the CAV equation, integration over magnitude within the PSHA typically begins at $\mathbf{M}=4.0$, with many earthquake motions between $\mathbf{M} 4.0$ to 5.0 being filtered out, as illustrated in Figure 5.

The effect of the CAV equation on seismic hazard is shown in Figure 6, which plots PGA and $1 \mathrm{~Hz}$ hazard curves with and without CAV. Using the CAV equation results in hazard curves that roll over to a horizontal asymptote at low amplitudes, which is the frequency of damaging earthquakes in the PSHA. Because of the definition of CAV (Equation (2)) and the correlation of low-frequency and PGA motions (from their median values given $\mathbf{M}$ and $\mathrm{R}$ ), the PGA and $1 \mathrm{~Hz}$ hazard curves roll over to the same horizontal asymptote. This is consistent with CAV being a broad-band measure of the damage potential of ground motions for structures with a wide range of natural frequencies.

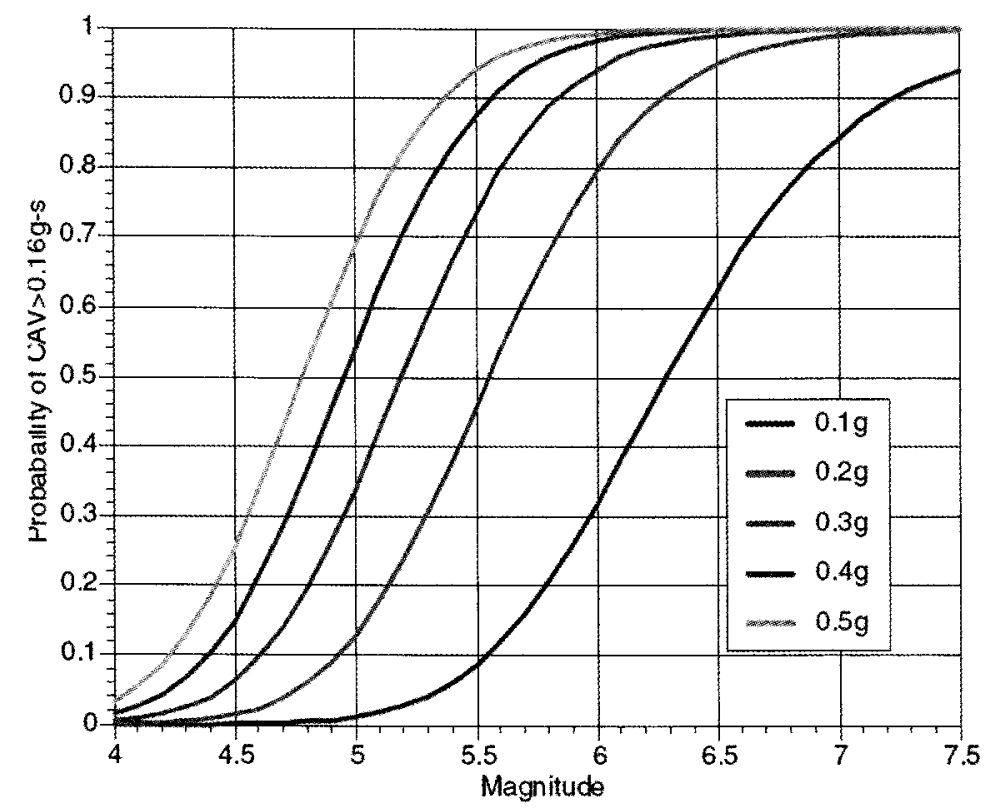

Fig. 5. $\mathrm{P}(\mathrm{CAV} \geq 0.16 \mathrm{~g}-\mathrm{sec})$ as a Function of $\mathbf{M}$ and $\mathrm{PGA}$ Amplitude for $\mathrm{V}_{\mathrm{s} 30}=1000 \mathrm{~m} / \mathrm{s}$. Note : Lowest Curve is for $\mathrm{PGA}=0.1 \mathrm{~g}$, Highest Curve is for PGA $=0.5 \mathrm{~g}$ (Source: Ref. 11) 
CAV and no-CAV hazard curves for example site

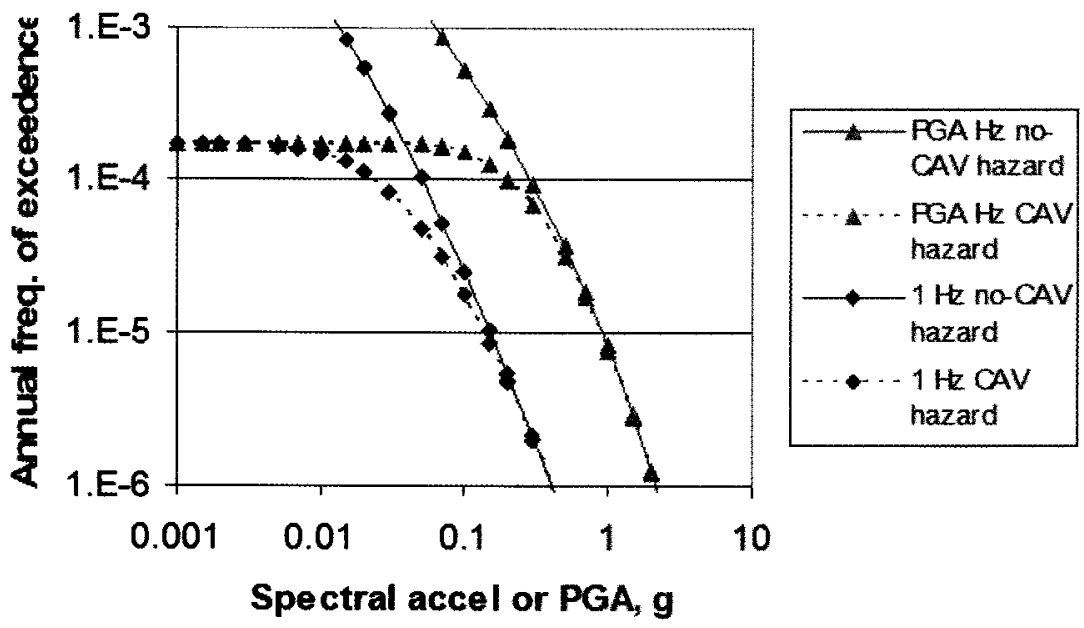

Fig. 6. Typical PGA and $1 \mathrm{~Hz}$ Spectral Acceleration Hazard Curves with and without CAV. (Source: Ref. 9)

Experience with the CAV equation shows that it has the most effect at sites where the hazard is controlled by frequent, small-to-moderate earthquakes. At sites dominated by larger magnitude earthquakes, the application of CAV does not have a large effect.

\section{CHOOSING DESIGN MOTIONS}

Seismic design ground motions for US nuclear plants are specified by a design spectrum, which is determined from uniform hazard response spectra (UHRS) calculated from a PSHA. The procedure follows one developed in Ref. 12. For the most critical structures and components, the seismic design spectrum is calculated using the $10^{-4}$ and $10^{-5}$ spectral amplitudes at each spectral frequency (these are the spectral amplitudes forming the $10^{-4}$ and $10^{-5}$ UHRS). A design factor DF is calculated as follows for each spectral frequency:

$$
\begin{gathered}
A_{R}=\operatorname{SA}\left(10^{-5}\right) / \mathrm{SA}\left(10^{-4}\right) \\
\mathrm{DF}=0.6 \mathrm{~A}_{\mathrm{R}}^{0.8}
\end{gathered}
$$

where $A_{R}$ is the ratio of spectral amplitudes at $10^{-5}$ and $10^{-4}$. The ground motion response spectrum (GMRS) used for design is then calculated as:

$$
\mathrm{GMRS}=\mathrm{SA}\left(10^{-4}\right) \times \max (1.0, \mathrm{DF})
$$

In addition there is the following criterion for the minimum GMRS:

$$
\text { GMRS } \geq 0.45 \mathrm{SA}\left(10^{-5}\right)
$$

Using this procedure ensures that a performance goal will be achieved. This performance goal is that the annual frequency of significant inelastic deformation of individual components subjected to seismic motion will be less than about $10^{-5}$ (Ref. 13). Projecting the overall seismic effects on a hypothetical nuclear plant designed to this level, a plantlevel performance goal can be achieved. This performance goal is that the mean annul seismic core damage frequency (SCDF) will be less than about $0.4 \times 10^{-5}$, which is less than the median annual SCDF calculated by Probabilistic Risk Assessment studies at 28 currently operating US nuclear power plants, which is $1.2 \times 10^{-5}$ (Ref. 14). This means that seismic designs following Eqns. (4) and (5) will achieve a higher level of seismic safety than existing plants.

\section{THE PRECISION OF SEISMIC HAZARD ESTIMATES}

An area that has received some attention in the past year has been in estimating the precision of PSHA results. Expert groups providing inputs to seismic hazard calculations are asked to quantify epistemic uncertainties in their inputs, and expert judgment is often used as a part of that quantification. As a result, if a different group of equally qualified experts were given the same fundamental seismic data for a region (the same historical earthquake catalog, 
tectonic maps, ground motion data, site profile information, etc.), that group would derive a slightly different set of inputs and epistemic uncertainties, resulting in a slightly different estimate of mean hazard. Thus any estimate of hazard has some associated imprecision, regardless of how many experts are used in the assessment and how qualified they are.

It is important to recognize this imprecision and to try to quantify it, to evaluate the significance of possible future changes caused by new hypotheses or new data. For example, a PSHA conducted today will be based on rates of occurrence of earthquakes in the historical and instrument record. If, ten years from now, rates of occurrence have increased by $5 \%$, the seismic hazard would also increase (by $5 \%$ on the frequency of exceedence axis). Is this change of $5 \%$ significant, and should it prompt re-evaluation of a nuclear plant's seismic design basis? Or is it within the precision with which we can assess seismic hazard, given today's models of earthquake occurrence, ground motion generation, and site response?

The precision of current seismic hazard estimates is being addressed in a project jointly funded by the US Nuclear Regulatory Commission, the US Dept. of Energy, and the US nuclear utilities. The precision is being estimated using results from large PSHA studies with multiple expert opinions that have been conducted in the US and Europe. Results should be available in 2010 .

\section{SUMMARY}

Probabilistic seismic hazard analyses as currently conducted in the US have a strong technical basis and can be used for decisions regarding seismic design levels. Many advances have been made in recent years in understanding the sizes and mean recurrence intervals of moderate-tolarge earthquakes in the eastern US. In spite of these advances, uncertainties are inevitable because these earthquakes are rare, and alternative hypotheses on earthquake occurrences and ground motions can only be resolved with empirical data. Some of these uncertainties are related to the indirect techniques that are available to estimate mean recurrence intervals, i.e. the location and dating of paleoliquefaction features from pre-historic earthquakes. Other uncertainties are related to the lack of strong motion data in stable tectonic regions around the world. Finally, uncertainties remain in how to estimate site response during strong shaking, even for sites that have numerous drill holes for sampling and an extensive dynamic laboratory testing program for those samples.

One of the advantages of PSHA is that these epistemic uncertainties can be quantified and processed in a consistent, logical way, to obtain mean estimates of seismic hazard given today's knowledge. The performance-based approach to choosing seismic design levels leads to the following result. Sites with larger uncertainties in earthquake characteristics will be designed to higher, more conservative ground motions than sites where uncertainties have been resolved, all other factors being the same. This gives credibility to the decision process and ensures that target performance levels (in terms of annual probabilities of unacceptable performance) will be achieved.

\section{ACKNOWLEDGMENTS}

The author appreciates the review of an early draft of the paper by Jon Ake and Gabriel Toro, who made many useful comments. The author also acknowledges the Electric Power Research Institute, which supported development of some of the results reported here.

\section{REFERENCES}

[1] R. K. McGuire, "Probabilistic seismic hazard analysis: Early history," Earth. Eng. Siruct. Dyn., 37, 329-338 (2008).

[2] M. McCann, Jr., J. Marrone and R. Youngs, "CEUS ground motion project final report," 1009684, Elec. Power Res. Inst. (2004).

[3] Risk Engineering, Inc., "Technical basis for revision of regulatory guidance on design ground motions: hazard- and risk-consistent ground motion spectra guidelines," NUREG/ CR-6728, U.S. Nuc. Reg. Comm. (2001).

[4] P. Bazzuro and C. A. Cornell, "Nonlinear Soil-Site Effects in Probabilistic Seismic-Hazard Analysis," Bull. Seis. Soc. of Amer., 94, 6, 2110-2123 (2004).

[5] C. H. Cramer, "Site-Specific Seismic-Hazard Analysis that is Completely Probabilistic," Bull. Seis. Soc. of Amer., 93, 4, 1841-1846 (2003)

[6] R. K. MoGuire, Seismic Hazard and Risk Anabysis, Monograph MNO-10, Earthq. Eng. Res. Inst., Oakland, CA (2004).

[7] Unistar Nuclear, "Calvert Cliffs Power Plant Unit 3 COLA (Final Safety Analysis Report), Rev, 4 - Chapter 02-Site Characteristics-Geology, Seismology, and Geotechnical Engineering- Section 2.5 - Part 04 - Pages 1396-1434," ML090860086, US Nuc. Reg. Comm. (2009).

[8] USNRC, "A performance-base approach to define the sitespecific earthquake ground motion," U.S. Nuc. Reg. Comm. Reg. Guide 1.208 (2007).

[9] Risk Engineering, Inc., "Technical basis for revision of regulatory guidance on design ground motions: development of hazard- and risk-consistent seismic spectra for two sites," NUREG/CR-6769, U.S. Nuc. Reg. Comm. (2002).

[10] M. W. McCann and J. W. Reed, "Proceedings: Engineering characterization of Small-Magnitude Earthquakes," NP3689, Elec. Power Res. Inst. (1989).

[11] N. Abrahamson and J. Watson-Lamprey, "Program on technology innovation: use of cumulative absolute velocity (CAV) in determining effects of small magnitude earthquakes on seismic hazard analysis," 1014099, Elec. Power Res. Inst. (2006). http://my.epri.com/portal/server.pt?Abstract_id $=000000000001014099$.

[12] ASCE, "Seismic design criteria for structures, systems, and components in nuclear facilities," ASCE/SEI 43-05, Amer. Soc. Civil Engrs. (2005).

[13] R. K. McGuire, "Program on technology innovation: sensitivity of performance-based approaches for determining the safe shutdown earthquake (SSE) ground motion for new plant sites," 1014379, Elec. Power Res. Inst. (2006). 
ROBIN K. MCGUIRE Issues in Probabilistic Seismic Hazard Analysis for Nuclear Facilities in the US

Available from http://my.epri.com/portal/server.pt?Abstract_id $=000000000001014379$.

[14] R. K. McGuire, "Program on technology innovation: assessment of a performance-based approaches for determining seismic ground motions for new plant sites," 2 Vols, 1012044, Elec. Power Res. Inst. (2005). Available from http://my.epri.com/portal/server.pt?Abstract_id $=000000000001012044$. 